\title{
MANAJEMEN RISIKO PADA PROYEK KONSTRUKSI DENGAN METODE FAST TRACK STUDI KASUS PROYEK QUNCI VILLAS DAN PUTRI NAGA KOMODO
}

\author{
I Gusti Ketut Wirawan ${ }^{1}$, I K. Sudarsana ${ }^{2}$, IBN. Purbawijaya ${ }^{2}$
}

\begin{abstract}
Abstrak : Perkembangan ekonomi yang pesat seperti saat ini, memerlukan suatu metode konstruksi yang dapat menyediakan fasilitas yang lebih cepat dengan biaya yang lebih murah. Oleh karena itu, metode fast track telah banyak diterapkan dalam pengelolaan proyek seperti yang terjadi pada Proyek Qunci Villas di Lombok dan Proyek Putri Naga Komodo di Loh Liang Pulau Komodo. Metode konstruksi fast track berpotensi menimbulkan berbagai risiko yang dapat mengganggu keberhasilan proyek. Penelitian ini bertujuan untuk mengidentifikasi berbagai risiko terutama risiko dominan, merumuskan langkah-langkah pengendalian risiko dan menentukan kepemilikan risikonya.

Penelitian ini dilakukan dengan metode deskriptif kualitatif dengan melakukan identifikasi risiko yang timbul selama pelaksanaan metode fast track pada Proyek Qunci Villas dan Proyek Putri Naga Komodo melalui studi literatur, brainstorming, wawancara dengan menggunakan kuesioner kepada pihak-pihak yang mengetahui atau terlibat dalam proyek tersebut. Sehingga dapat diketahui frekuensi dan besarnya konsekuensi dari masing-masing risiko. Kemudian dilakukan penilaian risiko untuk menentukan mayor risk dan minor risk. Kemudian dirumuskan langkah-langkah pengendalian risiko untuk mayor risk untuk mengurangi dampak negatif yang mungkin timbul. Agar pegendalian risiko dapat berjalan dengan baik maka dilakukan pengalokaian kepemilikan risiko.

Risiko yang teridentifikasi sebanyak 25 risiko yang terdiri dari 1 risiko (4\%) dengan peringkat medium risk, 6 risiko (24\%) dengan peringkat high risk, dan 18 risiko (72\%) dengan peringkat extreme risk. Risiko dominan (mayor risk) berjumlah 24 risiko (96\%). Risiko dominan dengan peringkat high risk terdiri dari : 1 risiko perencanaan, 3 risiko teknis, 1 risiko proyek, dan 1 risiko kriminal. Sedangkan risiko dominan dengan peringkat extreme risk terdiri dari : 5 risiko teknis, 10 risiko proyek, 2 risiko keuangan dan 1 risko manusia. Langkah-langkah pengendalian risiko dilakukan dengan cara mengurangi frekuensi dan konsekuensi risiko. Jumlah risiko terbanyak dialokasikan kepada pihak kontraktor.
\end{abstract}

Kata kunci : fast track, menejemen risiko, mitigasi risiko.

\section{RISK MANAGEMENT IN CONSTRUCTION PROJECT WITH FAST TRACK METHOD CASE STUDY QUNCI VILLAS AND PUTRI NAGA KOMODO PROJECT}

\begin{abstract}
The rapid economic development such as now day, it need a construction method that may provide a facility faster and less cost. Therefore, fast track method has been widely applied in project management as happened in Qunci Villas Project at Lombok and Putri Naga Komodo Project at Loh Liang of Komodo Island. Fast track construction method has potential risks that can interfere the success of the project. This study aims to identify the risks, especially the mayor risk, to formulate the mitigation action, and to determine the risk ownership.

This study was conducted using qualitative descriptive method by identifying the risks arising during the implementation of the fast track method on Qunci Villas and Putri Naga Komodo Projects through the study of literature, brainstorming, interview using questionnaires to those who knew or were involved in the project. So the frequency and magnitude of the consequences of each risk can be known. Then the risk assessment can be conducted to determine the mayor risk and the minor risk. Then determining mitigation action for the mayor risk to reduce the negative impact that may arise. Then allocating the risk ownership in other to the mitigation action can be handled properly.

The risk identified totaled 25 risks consisting of : 1 risk (4\%) which was medium risk rating, 6 risks $(24 \%)$ which were high risk rating, and 18 risks (72\%) which were extreme risk rating. The mayor risk amounted to 24 risks (96\%). The mayor risk which were high risk rating consisting of : 1 planning risk, 3 technical risks, 1 project risk and 1 criminal risk. While mayor risk which were extreme risk rating consisting of : 5 technical risks, 10 project risks, 2 financial risks, and 1 human risk. Mitigation action were handled by reducing likelihood and consequence. The most risks ownership were allocated to the contractor.
\end{abstract}

Key word : fast track, risk management, risk mitigation

\footnotetext{
${ }^{1}$ Mahasiswa Program Studi Magister Teknik Sipil, Program Pascasarjana, Universitas Udayana, Denpasar

${ }^{2}$ Staf Pengajar Program Studi Magister Teknik Sipil, Program Pascasarjana, Universitas Udayana, Denpasar
} 


\section{PENDAHULUAN \\ Latar Belakang}

Menurut Soeharto (1988), kegiatan proyek adalah suatu kegiatan yang berlangsung dalam waktu terbatas, dengan alokasi sumber daya tertentu dan dimaksudkan untuk menghasilkan produk atau devirerable yang kriteria mutunya sudah digariskan dengan jelas. Nieuwenburg (2004) Proyek yang dikelola secara tradisional memerlukan waktu yang lebih lama dibandingkan dengan proyek yang dikelola dengan metode fast track dalam penyelesaiannnya. Karena tahapan-tahapan proyek yang dikerjakan secara traditional dilaksanakan secara berurutan misalnya pelaksanaan konstruksi tidak bisa dilaksanakan sebelum proses perencanaan selesai $100 \%$ sedangkan tahapan-tahapan proyek yang dikerjakan secara fast track dilaksanakan secara bersamaan atau paralel misalnya pelaksanaan konstruksi sudah dapat dilaksanakan tanpa menunggu proses perencanaan selesai $100 \%$. Perkembangan ekonomi yang pesat seperti saat ini, memerlukan suatu metode konstruksi yang dapat menyediakan fasilitas yang lebih cepat dengan biaya yang lebih murah. Hal ini diperlukan untuk meningkatkan daya saing sehingga meningkatkan keuntungan perusahaan. Oleh karena itu, pada saat ini telah banyak diterapkan metode fast track dalam pengelolaan proyek seperti yang terjadi pada Proyek Qunci Villas di Lombok dan Proyek Putri Naga Komodo di Loh Liang Pulau Komodo.

Menurut James, (2012) penerapan metode fast track dalam pengelolaan proyek memberikan banyak keuntungan antara lain waktu penyelesaian proyek menjadi lebih cepat, biaya penyelesaian proyek menjadi lebih rendah dan meningkatkan reputasi pemilik sehingga menawarkan peluang bisnis lebih lanjut dalam pasar yang kompetitif. Penerapan metode fast track juga memiliki risiko yang sangat besar karena gambar yang dijadikan acuan dalam pelaksanaan masih belum lengkap atau sempurna yang sewaktu-waktu dapat berubah tergantung dari komunikasi antara owner dan arsitek. Umumnya risiko yang terjadi antara lain kemungkinan harus mengulang pekerjaan yang keliru/salah yang disebabkan pengambilan asumsi yang salah atau perubahan desain. Setiap penundaan dalam pengambilan keputusan seringkali menyebabkan penundaan dalam penyelesaian pekerjaan. Setiap perubahan desain maupun penundaan pekerjaan akan sangat berpengaruh dalam produktivitas dan biaya proyek. Oleh karena itu biaya yang tepat untuk proyek yang dikelola secara fast track tidak dapat diketahui sampai selesainya rencana dan pelaksanaan proyek. Meskipun anggaran untuk proyek tersebut dapat diperkirakan, sulit untuk mengatasi setiap kemungkinan adanya potensi perbedaan yang besar antara biaya yang diharapkan dan biaya yang sebenarnya.

Proyek dengan metode fast track berpotensi menimbulkan berbagai macam risiko yang dapat mengganggu keberhasilan proyek. Oleh karena itu, perlu dilakukan manajemen risiko untuk mengetahui berbagai risiko yang mungkin timbul dan bagaimana cara mengatasinya.

\section{Rumusan Masalah}

Berdasarkan uraian pada latar belakang masalah di atas, maka masalah pada penelitian ini dapat dirumuskan sebagai berikut :

1. Risiko-risiko apa saja yang teridentifikasi dalam metode konstruksi fast track pada Proyek Qunci Villas Lombok dan Proyek Putri Naga Komodo di Loh Liang Pulau Komodo?

2. Berapa jumlah risiko yang termasuk katagori dominan dalam metode konstruksi fast track pada Proyek Qunci Villas Lombok dan Proyek Putri Naga Komodo di Loh Liang Pulau Komodo?

3. Bagaimana tindakan pengendalian risiko (risk response) dalam metode konstruksi fast track pada Proyek Qunci Villas Lombok dan Proyek Putri Naga Komodo di Loh Liang Pulau Komodo?

4. Bagaimana pengalokasian kepemilikan risiko (ownership of risk) terhadap risiko-risiko dominan (major risk) dalam metode konstruksi fast track pada Proyek Qunci Villas Lombok dan Proyek Putri Naga Komodo di Loh Liang Pulau Komodo?

\section{Tujuan Penelitian}

Penelitian ini memiliki tujuan sebagai berikut :

1. Untuk mengetahui risiko-risiko apa saja yang teridentifikasi dalam metode konstruksi fast track pada Proyek Qunci Villas Lombok dan Proyek 
Putri Naga Komodo di Loh Liang Pulau Komodo.

2. Untuk mengetahui jumlah risiko yang termasuk katagori dominan dalam metode konstruksi fast track pada Proyek Qunci Villas Lombok dan Proyek Putri Naga Komodo di Loh Liang Pulau Komodo.

3. Untuk mengetahui tindakan pengendalian risiko (risk response) dalam metode konstruksi fast track pada Proyek Qunci Villas Lombok dan Proyek Putri Naga Komodo di Loh Liang Pulau Komodo.

4. Untuk mengetahui pengalokasian kepemilikan risiko (ownership of risk) terhadap risiko-risiko dominan (major risk) dalam metode konstruksi fast track pada Proyek Qunci Villas Lombok dan Proyek Putri Naga Komodo di Loh Liang Pulau Komodo.

\section{KAJIAN PUSTAKA \\ Pengertian Risiko}

Menurut Darmawi (2006) risiko dikaitkan dengan kemungkinan terjadinya akibat buruk yang tidak diinginkan atau tidak terduga. Dengan kata lain "Kemungkinan" itu sudah menunjukan adanya ketidakpastian. Ketidakpastian itu adalah kondisi yang dapat mengakibatkan timbulnya risiko. Sementara menurut Ramli (2009) risiko adalah kombinansi dari kemungkinan dan keparahan dari suatu kejadian.

Terdapat beberapa definisi risiko yang dikemukakan oleh Vaughan (1978) sebagai berikut :

1. Risk is the chance of loss (risiko adalah kans kerugian)

Chance of Loss biasanya dipergunakan untuk menunjukkan suatu keadaan dimana terdapat suatu keterbukaan terhadap kerugian. Sebaliknya jika disesuaikan dengan istilah yang dipakai dalam statistik, maka chance sering dipergunakan untuk menunjukkan tingkat probabilitas akan munculnya situasi tertentu.

2. Risk is the possibility of loss (risiko adalah kemungkinan kerugian)

Istilah possibility berarti bahwa probabilitas sesuatu kejadian berada di antara nol dan satu. Definisi ini barangkali sangat mendekati dengan pengertian risiko yang dipakai seharihari, akan tetapi definisi ini agak longgar, tidak cocok dipakai dalam analisis secara kuantitatif.

3. Risk is uncertainty (risiko adalah ketidakpastian)

Tampaknya ada kesepakatan bahwa risiko berkaitan dengan ketidakpastian. Karena itulah ada penulis yang berpendapat bahwa risiko memiliki arti yang sama dengan ketidakpastian.

Berdasarkan berbagai definisi di atas, dapat disimpulkan bahwa risiko adalah kemungkinan suatu peristiwa yang dapat menimbulkan ancaman maupun peluang.

\section{Manajemen risiko}

Menurut $\quad$ PMBOK $^{@}$ Guide (2004) Manajemen risiko adalah proses yang sistematik dari identifikasi, analisis, dan pengendalian risiko proyek. Tujuan manajemen risiko adalah memaksimalkan peluang dan konsekuensi dari kejadiankejadian yang positif dan meminimalkan peluang dan konsekuensi dari kejadiankejadian negatif terhadap sasaran proyek.

Menurut Kerzner (1995) manajemen risiko adalah cara yang sistematis untuk mengidentifikasi, mengukur risiko, memilih dan mengatur pilihan untuk menangani risiko. Sistem manajemen risiko dimulai dari mengidentifikasi risiko dilanjutkan dengan menghitung risiko dan pengaruhnya terhadap proyek, hasilnya adalah apakah risiko itu dapat diterima atau tidak.

Menurut AS/NZS $4360 \quad$ (2004) manajemen risiko menyangkut budaya, proses, dan struktur dalam mengelola suatu risiko secara efektif dan terencana dalam suatu sistem manajemen yang baik. Manajemen risiko adalah bagian integral dari proses manajemen yang berjalan dalam perusahaan atau lembaga.

Dari uraian berbagai definisi di atas maka, dapat disimpulkan bahwa manajemen risiko adalah proses yang terstruktur dalam mengelola risiko mulai dari identifikasi, analisis, sampai mitigasi risiko.

Menurut standar AS/NZS 4360 (2004) proses manajemen risiko terdiri dari enam tahapan yakni penentuan konteks, identifikasi risiko, penilaian risiko, evaluasi risiko, pemantauan dan tinjau ulang serta komunikasi dan konsultasi. Pada setiap tahapan dilakukan pemantauan dan tinjau ulang untuk mengetahui apakah langkah yang diambil sudah tepat dan apakah selama pelaksanaannya terdapat kekurangan sehingga perlu dilakukan 
perbaikan atau tinjau ulang. Pada setiap tahapan juga dilakukan komunikasi dan konsultasi dengan semua pihak yang terlibat atau terkena dampak dari setiap langkah yang diambil. Adapun gambaran mengenai proeses manajemen tersebut dapat dilihat pada Gambar 1.

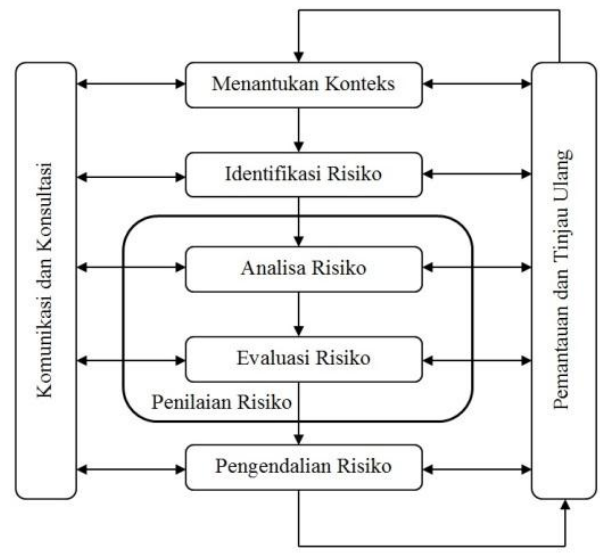

Gambar 1

Tahapan Manajemen Risiko

(Sumber :standar AS/NZS 4360, 2004)

\section{Pengertian Proyek}

Menurut Nugraha (1985) menyatakan bahwa proyek adalah sebuah proses pengadaan dari yang tidak ada menjadi ada dalam waktu yang tertentu.

Menurut Soeharto (1988) kegiatan proyek adalah suatu kegiatan yang berlangsung dalam waktu terbatas, dengan alokasi sumber daya tertentu dan dimagsudkan untuk menghasilkan produk atau devirerable yang kriteria mutunya sudah digariskan dengan jelas.

Menurut PMBOK@ Guide (2004) proyek adalah suatu upaya sementara yang dilaksanakan untuk membuat produk, layanan, atau hasil yang unik.

Dari definisi tersebut dapat disimpulkan bahwa proyek adalah suatu kegiatan yang bersifat sementara untuk menghasilkan produk yang unik.

\section{Proyek Fast Track}

Menurut Squires dan Murphy (1983), proses fast track didefinisikan sebagai sebuah metode konstruksi di mana konstruksi sebenarnya dimulai sebelum selesainya semua desain, perencanaan, penawaran, dan tahapan subkontrak dalam rangka untuk mengurangi efek inflasi.

Menurut James (2012) konstruksi fast Track pada dasarnya adalah konstruksi dilakukan secara bertahap, yang dimulai sebelum penyelesaian rencana dan spesifikasi.
Williams (1995) dalam Kasim.dkk (2005), mengemukakan bahwa proyek fast track adalah proyek yang dapat diselesaikan dalam waktu kurang dari $70 \%$ dari durasi proyek tradisional. Proyek fast track sangat erat kaitannya dengan waktu atau durasi yang perlu dipersingkat dengan tumpang tindih kegiatan atau menggunakan pendekatn rekayasa/engeneering secara bersamaan.

Dari berbagai definisi di atas, dapat disimpulkan bahwa proyek fast track adalah metode plekasanaan proyek yang dilaksanakan secara pararel atau tumpang tindih antara tahapan desain dan konstruksi sehingga proyek dapat diselesaikan dengan lebih cepat.

\section{Pengumpulan Data}

Menurut Siregar (2010), pengumpulan data adalah suatau proses pengumpulan data primer dan sekunder dalam suatu penelitian. Pengumpulan data merupakan langkah yang sangat penting, karena data yang akan dikumpulkan akan digunakan untuk pemecahan masalah yang sedang diteliti atau untuk menguji hipotesis yang telah dirumuskan.

Menurut Sugiyono (2002) dalam Siregar (2010), metode pengumpulan data yang digunakan dalam penelitian adalah : wawancara, kuesioner, dan observasi.

\section{Uji Validitas dan Reliabilitas}

Menurut Siregar (2010), validitas atau kesahihan adalah menunjukkan sejauh mana suatu alat ukur mampu mengukur apa yang ingin diukur. Menurut Siregar (2010), Suatu instrumen penelitian dikatakan valid, bila :

1. Jika koefiseian korelasi product moment melebihi 0,3 (Soegiyono, 1999 dan Siregar, 2010)

2. Nilai Sig. $\leq \alpha$

3. Jika korelasi product moment $>$ r-tabel $(\alpha ; n-2), n=$ jumlah sampel.

Rumus yang bisa digunakan untuk uji validitas menggunakan teknik korelasi product moment adalah

Rumus :

$$
r \quad \frac{n\left(\sum X Y\right)-\left(\sum X\right)\left(\sum Y\right)}{\sqrt{\left[n\left(\sum X^{2}\right)-\left(\sum X\right)^{2}\right]\left[n\left(\sum Y^{2}\right)-\left(\sum Y\right)^{2}\right]}}
$$

Menurut Siregar (2010), reliabilitas adalah untuk mengetahui sejauh mana hasil pengukuran tetap konsisten, apabila dilakukan pengukuran dua kali atau lebih terhadap gejala yang sama dengan menggunakan alat pengukur 
yang sama pula. Kreteria suatu instrumen penelitian dikatakan reliabel dengan menggunakan metode alpha cronbach, bila koefisien reliabilitas $\left(\mathrm{r}_{11}\right)>0,6$. Rumus yang bisa digunakan untuk uji reliabilitas menggunakan metode alpha cronbach sebagai berikut :

$$
\left.\mathrm{r}_{11}=\left[\frac{\mathrm{k}}{\mathrm{k}-1}\right] 1-\frac{1-\Sigma \sigma_{\mathrm{b}}^{2}}{\sigma_{\mathrm{t}}^{2}}\right]
$$

\section{METODE PENELITIAN \\ Rancangan Penelitian}

Penelitian pada proyek dengan metode fast track dilakukan dengan metode penelitian deskriptif kualitatif. Metode deskriptif kualitatif bertujuan untuk membuat deskripsi secara sistematik, faktual, dan akurat mengenai fenomena atau hubungan antar fenomena yang akan diteliti.

\section{Lokasi Penelitian}

Penelitian ini dilakukan pada tiga proyek konstrukasi dengan metode fast track yakni proyek Qunci Villas 2 dan proyek Qunci 3 yang terletak di Jalan Raya Mangsit, Senggigi, Kabupaten Lombok Barat, Provinsi Nusa Tenggara Barat dan Proyek Putri Naga Komodo terletak di Loh Liang Pulau Komodo, Provinsi Nusa Tenggara Timur. Waktu penelitian dimulai dari bulan April 2013 sampai November 2013.

\section{Tahapan Penelitian}

Penelitian ini terdiri dari beberapa tahapan sebagai berikut :

1. Pengumpulan data sekunder. Data sekunder diperoleh dari paper penelitian sejenis yang terkait dengan risiko pada proyek bangunan gedung. Berdasarkan data sekunder akan diperoleh indentifikasi risiko awal yang kemudian akan dikembangkan dengan data primer.

2. Penentuan konteks dilakukan sesuai dengan pandangan Mekanisari (2009), yakni dengan menentukan batasanbatasan atau lingkungan yang dapat memepengaruhi baik langsung maupun tidak langsung proyek yang diteili antara lain : kondisi proyek, pihak-pihak yang terlibat, waktu pelaksanaan. Pada tahap ini juga ditentukan Sesuai dengan padangan Ramli (2009), pada tahap ini juga mditentukan kriteria risiko yang digunakan sebagai berikut :

a. Kriteria risiko kemungkinan (likelihood) menggunakan standar AS/NZS 4360 : 2004 yang telah dikembangkan sesuai dengan proyek yang diteliti.

b. Kriteria risiko keparahan (concequency) menggunakan standar AS/NZS 4360 : 2004 dalam Australian Capital Territory Insurance Authority, 2004.

3. Tahap identifikasi risiko dilakukan sesuai pandangan Flanagan dan Norman (1993), yakni dimulai dengan mencari informasi dengan jelas terhadap sumber (source) risiko tersebut, kejadian atau peristiwa (event) dan akibat (effect) dari risiko tersebut. Sementara untuk penentuan sumber risko akan dilakukan sesuai dengan pandangan Menurut Godfrey (1996), yakni sumber risiko dibedakan menjadi 12 sumber risiko.

4. Kuisioner disusun dengan membuat lembaran berisi pertanyaan-pertanyaan yang diperoleh dari proses identifikasi risiko

5. Teknik sampling yang mengunakan metode porpusive sampling. Metode ini digunakan karena tidak semua orang mengetahui atau terlibat dalam proyek yang diteliti. Jumlah populasi diperoleh dari struktur organisasi masing-masing proyek khususnya dari pihak konsultan, kontraktor dan subkontraktor yakni sebanyak 18 orang. Dalam penelitian ini tingkat kesalahan diperkirakana sebanyak 5\%. Dengan menggunakan Teknik Solvin, ukuran sampel yang digunakan yang digunakan dalam penelitian ini sebagai berikut :

$$
=\frac{\mathrm{N}}{1+\mathrm{Ne}^{2}}=\frac{18}{1+18(0,05)^{2}}=17 \text { orang }
$$

Menurut Gay dan Diehl (1992) dalam Hendry (2012) Jika penelitiannya bersifat deskriptif, maka sampel minimumnya adalah $10 \%$ dari pupulasi. Jika dilihat dari struktur organisasi masing-masing proyek maka, total jumlah personil yang terlibat dalam pengelolaan proyek 
tersebut adalah sebanyak 78 orang. Jadi jumlah responden sebanyak 17 orang sudah memenuhi syarat $10 \%$ dari jumlah populasi proyek yang diteliti.

6. Uji instrument penelitian. Uji validitas digunakan untuk mengukur sah atau valid tidaknya suatu kuisioner. Uji validitas yang digunakan dalam penelitian ini adalah uji validitas konstruk (construct validity) yang dihitung secara manual. reliabilitas adalah untuk mengetahui sejauh mana hasil pengukuran tetap konsisten, apabila dilakukan pengukuran dua kali atau lebih terhadap gejala yang sama dengan menggunakan alat pengukur yang sama pula. Uji reliabiliitas dalam penelitian ini menggunakan metode alpha cronbach yang dihitung secara manual.

7. Pengumpulan data kuesioner. Pengumpulan data primer menggunakan metode kuisioner/interview dalam penelitian ini dimulai dari Bulan Juni 2013 sampai November 2013.

8. Analisis risiko dilakukan dengan menggunakan risk matrix AS/NZS 4360 : 2004 yang telah dikembangkan oleh Savage (2007), dimana skor risiko diperoleh dengan rumus risiko $=(($ likelihood $\mathrm{x} 2)+($ concequence $\mathrm{x}$ 3)) $\mathrm{x} 4$.

9. Evaluasi risiko dilakukan dengan cara menentukan prioritas risiko dengan menggunakan konsep ALARP untuk mengetahui apakah risiko tersebut dapat diterima atau tidak dapat diterima.

10. Pengendalian risiko tergantung dari hasil evaluasi risiko, untuk risiko yang tergolong tidak dapat diterima (major risk) perlu dilakukan pengendalian risiko. Adapun pilihan dalam pengendalian risiko akan menggunakan standar AS/NZS 4360.

11. Pada tahap ini akan dilakukan penilaian terhadap kepemilikan risiko (ownership of risk) yakni risiko tergolong dominan akan dialokasikan kepemilikannya pada pihak-pihak yang memiliki kopetensi dibidangnya sehingga tindakan mitigasi dapat dilaksanakan secara optimal. Dalam menentukan kepemilikan risiko (ownership of risk), menggunakan prinsip-prinsip pengalokasian risiko yang dikembangkan oleh Flanagan dan Norman (1993)

\section{HASIL DAN PEMBAHASAN Identifikasi Risiko}

Risiko yang teridentifikasi dalam penelitian metode konstruksi fast track pada Proyek Qunci Villas dan Proyek Putri Naga Komodo berjumlah 25 ( dua puluh lima) risiko. Dari 25 (dua puluh lima) risiko yang telah teridentifikasi, jumlah risiko terbanyak bersumber dari risiko proyek dengan prosentase sebesar $48 \%$. Sedangkan jumlah risiko terbanyak termasuk kategori faktor internal dengan prosentase sebesar $96 \%$.

\section{Pengujian Validitas dan Reliabilitas}

Jumlah responden yang digunakan dalam pengujian adalah 9 responden maka nilai $\mathrm{n}=9$, taraf signifikan yang digunakan dalam penelitian ini adalah $5 \%$ maka nilai $(\alpha)=0,05$. Sehingga dari tabel nilai-nilair Product Moment, nilai $r$ tabel $(0,05 ; 9-2)$ didapat sebesar 0,754. Dari hasil perhitungan validitas secara manual dengan rumus validitas konstruk didapat bahwa nilai $\mathrm{r}$ hitung masing-masing butir pertanyaan $>0,754$, maka pertanyaan koesioner mengenai frekuensi risiko dan konsekuensi terjadinya risiko dinyatakan valid.

Kreteria suatu instrumen penelitian dikatakan reliabel dengan menggunkan teknik alpha cronbach, bila koefisien reliabilitas $\left(\mathrm{r}_{11}\right)$ $>0,6$. Dari hasil perhitungan reliabilitas nilai koefisien reliabilitas $\left(\mathrm{r}_{11}\right)$ mengenai frekuensi risiko adalah $0,98>0,6$. Sementara nilai koefisien reliabilitas $\left(\mathrm{r}_{11}\right)$ mengenai konsekuensi terjadinya risiko adalah $0,95>$ 0,6 . Hal ini menunjukkan bahwa instrument penelitian yang digunakan adalah reliabel.

\section{Analisis Risiko}

Dari hasil analisis risiko dihasilkan bahwan tidak ada risiko dengan tingkat low risk, risiko dengan peringkat medium risk sebanyak 1 risiko (4\%), risiko dengan peringkat high risk sebanyak 6 risiko (24\%), dan risiko dengan peringkat extreme risk sebanyak 18 risiko (72\%).

\section{Evaluasi Risiko}

Risiko dengan peringkat high risk dan extreme risk merupakan risiko yang tidak dapat ditolelir atau risiko dominan (major risk), sehingga harus dilakukan langkah pencegahan. Major risk dalam proyek konstruksi dengan metode fast track berjumlah 24 risiko (96\%). risiko dominan dengan peringkat high risk terbanyak bersumber dari 
risiko teknis yakni sebanyak 3 risiko sedangkan risiko dominan dengan peringkat Extreme risk terbanyak bersumber dari risiko proyek yakni sebanyak 10 risiko.

Risiko dengan peringkat medium risk merupakan risiko yang tidak dominan sehingga dapat diabaikan. Minor risk dalam dalam proyek konstruksi dengan metode fast track pada proyek qunci villas dan putri naga komodo berjumlah 1 risiko (4\%) yang bersumber dari risiko proyek.

\section{Pengendalian Risiko}

Risiko-risiko dominan pada proyek konstruksi dengan metode fast track pada proyek qunci villas dan putri naga komodo perlu dikelola melalui tindakan pengendalian risiko, dengan cara mengurangi frekuensi risiko, mengurangi konsekuensi risiko dan menghindari risiko

\section{Kepemilikan Risiko}

kepemilikan risiko dengan peringkat high risk dialokasikan secara merata kepada pihak owner, arsitek maupun kontraktor. Sedangkan kepemilikan risiko dengan peringkat extreme risk terbanyak dialokasikan kepada pihak owner yakni sebanyak 18 risiko.

\section{SIMPULAN DAN SARAN \\ Simpulan}

Berdasarkan hasil dan pembahasan, maka dapat ditarik beberapa kesimpulan sebagai berikut :

1. Risiko yang teridentifikasi pada proyek konstruksi dengan metode fast track pada Proyek Qunci Villas di Lombok dan Proyek Putri Naga Komodo di Loh Liang Pulau Komodo adalah sebanyak 25 risiko, yang terdiri dari risiko proyek (12 risiko), risiko keuangan (2 risiko), risiko manusia (1 risiko), risiko kriminal (1 risiko), risiko perencanaan (1 risiko), risiko teknis (8 risiko). Dari 25 risiko yang teridentifikasi hanya terdapat 1 risiko dengan kategori risiko ekternal dan 24 risiko dengan kategori risiko internal. Sementara dari 25 risiko yang teridentifikasi terdapat 1 risiko (4\%) dengan peringkat medium risk, 6 risiko (24\%) dengan peringkat high risk, dan 18 risiko (72\%) dengan peringkat extreme risk.

2. Terdapat $96 \%$ risiko yang termasuk risiko dominan (major risk), yang terdiri dari 6 risiko (24\%) dengan peringkat high risk, dan 18 risiko $(72 \%)$ dengan peringkat extreme risk. Risiko dominan dengan peringkat high risk terdiri dari 1 risiko perencanaan, 3 risiko teknis, 1 risiko proyek, dan 1 risiko kriminal. Risiko dominan dengan peringkat extreme risk terdiri dari 5 risiko teknis, 10 risiko proyek, 2 risiko keuangan dan 1 risko manusia.

3. Risiko-risiko dominan pada proyek konstruksi dengan metode fast track pada Proyek Qunci Villas di Lombok dan Proyek Putri Naga Komodo di Loh Liang Pulau Komodo perlu dikelola melalui tindakan mengurangi frekuensi maupun konsekuensi risiko dengan cara antara lain menjalin komunikasi secara intensif baik melalui rapat, email, telpon, gambar kerja membahas masalah dan solusi yang terjadi. Melakukan seleksi terhadap tenaga kerja, menambah tenaga pengawas.

4. Pada proyek konstruksi dengan metode fast track pada Proyek Qunci Villas di Lombok dan Proyek Putri Naga Komodo di Loh Liang Pulau Komodo, yang berperan dalam melakukan tindakan mitigasi risiko adalah Owner, Arsitek sebagai konsultan perencana dan pengawas, dan kontraktor. Yang mana kepemilikan risoko terbanyak dialokasikan kepada pihak kontraktor.

\section{Saran}

Berdasarkan hasil penelitian dan simpulan di atas, maka dapat disampaikan saran-saran sebagai berikut :

1. Risiko-risiko yang tergolong risiko dominan (mayor risk) dapat dijadikan pedoman bagi pihak-pihak yang terlibat dalam melakukan tindakan mitigasi pada proyek konstruksi dengan metode fast track.

2. Perlu dilakukan penelitian lebih lanjut pada proyek yang memiliki skala konstruksi dan kompleksitas permasalahan yang lebih besar sehingga diperoleh identifikasi risiko yang lebih mendetail.

3. Setelah dilakukan tindakan pengendalian terhadap risiko-risiko dominan, perlu dilakukan penelitian lebih jauh menyagkut identifikasi dan penilaian terhadap risiko sisa (residual risk)

\section{DAFTAR PUSTAKA}

Anonim. 2004. A Guide To The Project Management Body of Knowledge Third 
Edition. (serial online), [cited 2014 july 19]. Available from : http://www.google.co.id/url?sa=t\&rct=j\& $\mathrm{q}=\&$ esrc $=\mathrm{s} \&$ source $=$ web $\& \mathrm{~cd}=7 \& \mathrm{cad}=\mathrm{rja}$ \&uact $=8 \&$ ved $=0$ CEQQFjAG\&url=http $\%$ $3 \mathrm{~A} \% 2 \mathrm{~F} \% 2 \mathrm{Fwww} \cdot \operatorname{maxwideman} . \operatorname{com} \% 2 \mathrm{~F}$ papers\%2Fpmbok3\%2Fpmbok3.pdf\&ei= SwfKU_XbL9K-

uATasoCAAw\&usg=AFQjCNFkbpVOm c7-

A1LSwPj2PV4eOE9HnQ\&bvm=bv.711 98958,d.c2E

Anonim. 2005. Risk Management Guidelines Companion To AS/NZS 4360:2004. (serial online), [cited 2014 july 5]. Available from

http://www.google.co.id/url?sa=t\&rct=j\& $\mathrm{q}=$ risk\%20matrix\%20as/nzs\%204360\&s ource $=$ web $\& c d=5 \& c a d=$ rja $\&$ uact $=8 \& v e$ d=0CDkQFjAE\&url=http://www.defence .gov.au/women/docs/5\%2520Risk\%2520 Management\%2520Plan.pdf\&ei=pa3U8r4LMyGuATw8oGoAQ\&usg=AF QjCNHI9rtD_YNXwb5FakL1rI2deQDY 9w\&bvm=bv.70138588,d.c2E

Darmawi, H. 2006. Manajemen Risiko. Jakarta : Bumi Aksara.

James, S.C. 2012. Fast-Track Construction. (serial online), [cited 2013 May 6]. Available from

http://www.stevencjames.com/newsletter s/construction-law/fast-trackconstruction/

Kasim N.B, Anumba C.J, Dainty A.R.J. 2005. Improving Materials Management Practices On Fast-Track Construction Project. (serial online), [cited 2013 May 7]. Available from http://www.arcom.ac.uk/docs/proceedings/ar2005-07930802 Kasim_Anumba and Dainty.pdf

Kezner, H. 1995. Project Management A System Approach to Planning Scheduling and Controlling. Fifth edition. New York : Van Nostrand Reinhold.

Nugraha, P. 1985. Manajemen Proyek Konstruksi 1. Surabaya : Kartika Yuda.

Ramli, S. 2009. Manajemen Risiko Dalam Perspektif K3 OHS Risk Management. Jakarta : Dian Rakyat
Siregar, S. 2010. Statistika Deskriptif Untuk Penelitian Dilengkapi Perhitungan Manual Dan Aplikasi SPSS Versi 17. Jakarta : Rajawali Pers

Soeharto, I. 1998. Manajemen Proyek Dari Konseptual Sampai Operasional, Jakarta : Erlangga

Squires W.R. dan Murphy M.J. 1983. The Impaxt Of Fast Track Construction And Construction Management On Subcontractors. (serial online), [cited 2013 may 6]. Available from : http://scholarship.law.duke.edu/cgi/viewc ontent.cgi ?article $=3687 \&$ context $=1 \mathrm{cp}$

Vaughan, E. J. 1978. Fundamental of Risk and Insurance. Second Edition. John Willey. 